\title{
Mechanical Properties of Self-Consolidating Concrete Using Conventional Concrete Models
}

\author{
by Angel Vilanova, Jaime Fernández-Gómez, and Galit Agranati Landsberger
}

The objective of this study is to analyze the applicability of current models used for estimating the mechanical properties of conventional concrete to self-consolidating concrete (SCC). The mechanical properties evaluated are modulus of elasticity, tensile strength, and modulus of rupture. As part of the study, it was necessary to build an extensive database that included the proportions and mechanical properties of 627 mixtures from 138 different references.

The same models that are currently used for calculating the mechanical properties of conventional concrete were applied to SCC to evaluate their applicability to this type of concrete. The models considered are the ACI 318, ACI 363R, and EC2. These are the most commonly used models worldwide. In the first part of the study, the overall behavior and adaptability of the different models to SCC is evaluated. The specific characterization parameters for each concrete mixture are used to calculate the various mechanical properties applying the different estimation models. The second part of the analysis consists of comparing the experimental results of all the mixtures included in the database with the estimated results to evaluate the applicability of these models to SCC. Various statistical procedures, such as regression analysis and residual analysis, are used to compare the predicted and measured properties.

It terms of general applicability, the evaluated models are suitable for estimating the modulus of elasticity, tensile strength, and modulus of rupture of SCC. These models have a rather low sensitivity, however, and adjust well only to mean values. This is because the models use the compressive strength as the main variable to characterize the concrete and do not consider other variables that affect these properties.

Keywords: model estimation; modulus of elasticity; modulus of rupture; self-consolidating concrete; tensile strength.

\section{INTRODUCTION}

Compared with conventional concrete, self-consolidating concrete (SCC) mixtures generally have higher powder content, a high content of high-range water-reducing agents (HRWRAs), lower gravel content, smaller maximum gravel diameter, and a higher paste volume. These modifications in the composition of the mixture affect the concrete's behavior in the fresh state, but also its mechanical properties in the hardened state.

It is generally considered that the mechanical properties of SCC and conventional, vibrated concrete (CC) are similar. There are different opinions on this subject, however, and further research is still needed. From evaluating numerous studies, it is clear that the conclusions regarding the mechanical properties of SCC in comparison to CC are not unanimous. For example, Attiogbe et al. ${ }^{1}$ concluded in his study that CC and SCC have equivalent moduli of elasticity. On the other hand, Holschemacher and $\mathrm{Klug}^{2}$ indicate that the modulus of elasticity of SCC is lower than that of CC. Regarding the tensile strength, Ouchi et al. ${ }^{3}$ reports that SCC and CC have equivalent tensile strength, whereas Marti et al. ${ }^{4}$ indicates that the tensile strength of SCC is higher. For the modulus of rupture, Leemann and Hoffman ${ }^{5}$ determined that it is similar for both concretes, whereas Turcry et al. ${ }^{6}$ found that it is higher for SCC. The differences in the mechanical properties of CC and SCC can be attributed to three main characteristics of SCC: modifications in the composition of the mixture, improvement of the microstructure of the concrete, and the fact that SCC does not require external consolidation when placed.

The modifications in the composition of the SCC refer to the high paste content and fine material; the lower water/ cement ratio $(w / c)$ and the lower water/powder ratio; the lower gravel content and the lower maximum diameter size of the gravel; and the use of HRWRAs and viscosity-modifying agents (VMAs). The improvement in the microstructure can be attributed to the characteristics of the paste and the lower porosity of the transition zone between the aggregate and the paste. The lower water/powder ratio-which is necessary, together with the HRWRA, to obtain adequate flowability-provides a more compact and homogeneous transition zone that, in turn, improves the mechanical characteristic of the concrete. In this type of concrete, because there is no need for external vibration, the problems that may result from the vibration process, such as segregation of the mixture or the formation of voids, do not occur.

Considering that the mechanical properties of SCC may vary from those of conventional concrete, and that the various estimating models for the calculation for these properties have not been modified for their application to SCC, it is necessary to confirm their applicability to this type of concrete.

\section{RESEARCH SIGNIFICANCE}

The mechanical properties of SCC have already been extensively researched, but most of these studies are based on individual experimental programs with a limited number of mixtures and tests, and their conclusions are not consistent and are even contradictory. Regarding the estimating models for calculating the mechanical properties of SCC, the current models have been developed and adjusted for conventional concrete, and there is still no large-scale study that evaluates whether the current models used in conventional concrete are also applicable to SCC, or that these have to be modified for their application.

The objective of this study is to analyze the applicability of the current models used for estimating mechanical properties of CC to SCC. The mechanical properties evaluated 
are modulus of elasticity, tensile strength, and modulus of rupture. Considering that the mixture composition of SCC is different from that of $\mathrm{CC}$, it is necessary to confirm the applicability of the existing estimating models for these to be used in the case of SCC.

As part of the study, it was necessary to build an extensive database so that the results of the analysis are not based on a few experimental results, but rather on a large and representative sample. The development of a database with the mechanical test results of SCC, which is to include the results of most available experimental investigations on $\mathrm{SCC}$, is of a particular significance in view of the evaluation of the current codes and their application to SCC.

\section{DATABASE}

The compiled database includes the mixture proportioning and mechanical properties from 138 different references. Most references are from articles published in scientific publications, publications of research centers, conferences and symposiums, and doctoral theses. The database includes a total of 627 mixtures for compressive strength, 193 for modulus of elasticity, 165 for indirect tensile strength, and 59 for modulus of rupture. The cement content varied between 133 and $665 \mathrm{~kg} / \mathrm{m}^{3}$ (8.2 and $41.2 \mathrm{lb} /$ $\left.\mathrm{ft}^{3}\right)$, with a mean value of $374 \mathrm{~kg} / \mathrm{m}^{3}\left(23.2 \mathrm{lb} / \mathrm{ft}^{3}\right)$. The $w / c$ value varied between and 0.26 and 1.34 , with a mean value of 0.51 . The water/binder ratio $(w / b)$ varied between and 0.34 and 0.8 , with a mean value of 0.34 . The mineral admixture content varied between 0 and $490 \mathrm{~kg} / \mathrm{m}^{3}\left(30.4 \mathrm{lb} / \mathrm{ft}^{3}\right)$, with a mean value of $158 \mathrm{~kg} / \mathrm{m}^{3}\left(9.8 \mathrm{lb} / \mathrm{ft}^{3}\right)$. The slump flow of the mixtures varied between 381 and $864 \mathrm{~mm}$ (14.9 and 33.7 in.), with a mean value of $699 \mathrm{~mm}$ (27.3 in.). Detailed information regarding the proportions and mechanical characteristics of all the mixtures is included in Reference 7. dance with EC2, Eq. (3.3), the direct tensile strength can be considered as $90 \%$ of the indirect tensile strength. In the case of the EC2 model, it was also necessary to convert the characteristic strength $f_{c k}$ to the mean compressive strength $f_{c m}$, using the EC2 expression

$$
f_{c k}(t)=f_{c m}(t)-8 \mathrm{MPa} \quad(8 \mathrm{MPa}=1160 \mathrm{psi})
$$

In the EC2 model, the modulus of rupture is defined in terms of the mean tensile strength and the mean height of the beam element. The mean tensile strength is transformed into the mean compressive strength using

$$
f_{c t m}=0.3\left(f_{c m}-8 \mathrm{MPa}\right)^{2 / 3}
$$

A specimen height of $150 \mathrm{~mm}$ (5.85 in.) is considered. This is substituted into the original equation.

\section{FACTORS AFFECTING MECHANICAL PROPERTIES OF SCC}

The composition of the mixture is directly related to the hardened mechanical properties of the concrete. Because the material properties and components vary widely between the mixtures, the effect of each of the variables is analyzed statistically. A common method for evaluating the relationship between two variables is by means of the correlation coefficient. In statistical analysis of data, the correlation between two variables indicates the strength and the direction of the relationship between the two. Two quantitative variables can be considered correlated if the values of one of them vary systematically with respect to the other.

In this study, a correlation analysis was done between the variables related to the mixtures and the mechanical properties of SCC. The variables considered are: cement content, total powder content, mineral admixtures, water, sand, gravel, $w / c$, water/powder ratio, sand/(sand + gravel) ratio, and maximum gravel diameter size. The mechanical properties evaluated are tensile strength, modulus of elasticity, and modulus of rupture.

\section{Table 1-Estimating equations of different models}

\begin{tabular}{c|c|c|c}
\hline Mechanical property & Source & Estimating model & Units \\
\hline \multirow{3}{*}{ Modulus of elasticity } & ACI 318 & $E_{c}=4700 \sqrt{ } f_{c}^{\prime}$ & $f_{c}^{\prime}:(\mathrm{MPa}) ; E_{c}:(\mathrm{MPa})$ \\
\cline { 2 - 4 } & $\mathrm{EC} 2$ & $E_{c}=22\left[f_{c m} / 10\right]^{0.3}$ & $f_{c m}:(\mathrm{MPa}) ; E_{c}:(\mathrm{GPa})$ \\
\cline { 2 - 4 } & $\mathrm{ACI} 363 \mathrm{R}$ & $E_{c}=3320 \sqrt{ } f_{c}^{\prime}+6900$ & $f_{c}^{\prime}:(\mathrm{MPa}) ; E_{c}:(\mathrm{MPa})$ \\
\hline \multirow{2}{*}{$\begin{array}{c}\text { Indirect } \\
\text { tensile strength }\end{array}$} & $\mathrm{ACI} 363 \mathrm{R}$ & $f_{c t, s p}=0.59\left(f_{c m}\right)^{1 / 2}$ & $f_{c m}:(\mathrm{MPa}) ; f_{c t, s p}:(\mathrm{MPa})$ \\
\cline { 2 - 4 } & $\mathrm{EC} 2$ & $f_{c t, s p}=1 / 3\left(f_{c m}-8 \mathrm{MPa}\right)^{2 / 3}$ & $f_{c m}:(\mathrm{MPa}) ; f_{c t, s p}:(\mathrm{MPa})$ \\
\hline \multirow{2}{*}{ Modulus of rupture } & $\mathrm{ACI} 363 \mathrm{R}$ & $f_{c f t}=0.94\left(f_{c m}\right)^{1 / 2}$ & $f_{c t m}:(\mathrm{MPa}) ; f_{c t, f f}:(\mathrm{MPa})$ \\
\cline { 2 - 4 } & $\mathrm{EC} 2$ & $f_{c t, f t}=0.435\left(f_{c m}-8 \mathrm{MPa}\right)^{2 / 3}$ & \\
\hline
\end{tabular}

Notes: $E_{c}$ is modulus of elasticity of concrete at 28 days; $f_{c}^{\prime}$ is characteristic compressive strength of concrete at 28 days; $f_{c m}$ is mean compressive strength of concrete at 28 days; $f_{c t, s p}$ is indirect tensile strength of concrete at 28 days; $f_{c f t}$ is modulus of rupture of concrete at 28 days; $f_{c t, f}$ is modulus of rupture of concrete at 28 days $(\mathrm{EC} 2) ; 1 \mathrm{MPa}=145 \mathrm{psi}$. 
Table 2-Correlation coefficient between mechanical properties and variables related to mixture proportions

\begin{tabular}{c|c|c|c|c|c|c|c|c|c|c|c}
\hline & Cement & $\begin{array}{c}\text { Total } \\
\text { powder } \\
\text { content }\end{array}$ & $\begin{array}{c}\text { Mineral } \\
\text { admixture } \\
\text { content }\end{array}$ & Water & Sand & Gravel & $w / c$ & $\begin{array}{c}\text { Water/ } \\
\text { powder } \\
\text { ratio }\end{array}$ & $\begin{array}{c}\text { Gravel/ } \\
\text { (gravel + } \\
\text { sand) ratio }\end{array}$ & $\begin{array}{c}\text { Maximum } \\
\text { gravel diameter }\end{array}$ & $\begin{array}{c}\text { Compressive } \\
\text { strength } f_{c}\end{array}$ \\
\hline$F_{c}$ & 0.66 & 0.40 & -0.27 & -0.25 & -0.10 & 0.08 & -0.66 & -0.51 & -0.15 & -0.03 & 1 \\
\hline $\begin{array}{c}\text { Modulus of } \\
\text { elasticity } E\end{array}$ & 0.26 & 0.09 & -0.15 & -0.27 & -0.17 & 0.15 & -0.37 & -0.3 & -0.37 & 0.37 \\
\hline $\begin{array}{c}\text { Tensile } \\
\text { strength } f_{c t}\end{array}$ & 0.59 & 0.34 & -0.23 & -0.2 & 0.12 & -0.10 & -0.51 & -0.41 & 0.13 & -0.29 & 0.64 \\
\hline $\begin{array}{c}\text { Modulus of } \\
\text { rupture } f_{c t, f}\end{array}$ & 0.43 & 0.26 & -0.15 & -0.16 & -0.24 & -0.04 & -0.46 & -0.38 & -0.43 & 0.28 & 0.77 \\
\hline
\end{tabular}

Considering that the estimating models for the tensile strength, modulus of elasticity, and modulus of rupture use the compressive strength as the main estimation parameter (and do not include any other dosification components in the models), it was important to also include the correlation between these mechanical properties and the compressive strength to evaluate if this simplification is justified or not. The values for the correlation coefficient are shown in Table 2.

It can be observed that there is no one variable related to the concrete mixture that has a significantly high correlation $(>0.90)$ with any of the considered mechanical properties. In the case of the modulus of elasticity, the highest correlation is with the $w / c$, followed by the cement content, water/powder ratio, and total powder content, with correlation values of $-0.662,0.659,-0.505$, and 0.404 , respectively.

For the tensile strength, the highest correlation is with the cement content, followed by the $w / c$, water/powder ratio, and total powder content, with correlation values of 0.593 , $-0.514,0.414$, and 0.338 , respectively.

For the modulus of rupture, the highest correlation is with the $w / c$, followed by the cement content, gravel/(gravel + sand) ratio, and water/powder ratio, with values of -0.456 , $0.434,0.431$, and 0.382 , respectively.

Regarding the compressive strength, the correlation coefficient has the highest value with the cement content, followed by the $w / c$, and the water/powder ratio, with values of 0.659 , 0.662 , and 0.505 , respectively.

For all three mechanical properties, the correlation with the compressive strength is higher than with any of the individual dosification variables. The correlation coefficient between the compressive strength and the modulus of elasticity, tensile strength, and modulus of rupture, is $0.64,0.77$, and 0.76 , respectively. The comparatively high correlation of these properties with the compressive strength justifies the use of the compressive strength as the main variable in the estimation of the other mechanical properties.

In the following sections, the various models will be analyzed separately for each of the mechanical properties considered.

\section{MODULUS OF ELASTICITY ESTIMATING MODELS}

Figure 1 shows the modulus of elasticity as a function of the compressive strength for all the mixtures included in the database and the corresponding best-fit curve. The best-fit curve is a potential equation with the format of $Y=a X^{b}$. Various curves were evaluated; however, this type of equation resulted as the best-adjusted curve. The figure also includes a comparison between the best-fit curve for the database and the corresponding relationship for the different estimating models. A general overview of the relationship between the
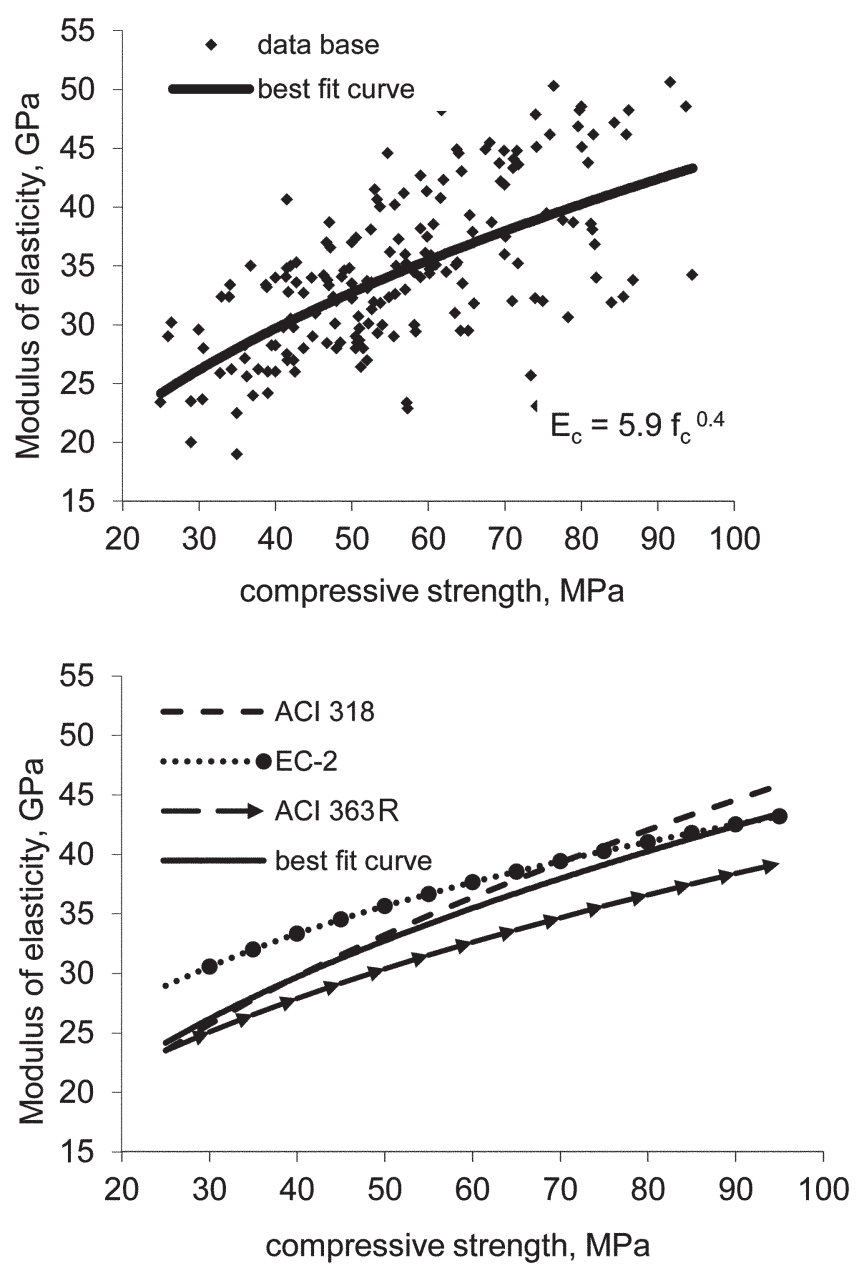

Fig. 1-Relationship between modulus of elasticity and compressive strength for mixtures included in database and different estimating models. (Note: $1 \mathrm{MPa}=145 \mathrm{psi}$; $1 \mathrm{GPa}=145,000 \mathrm{psi}$.)

modulus of elasticity and the compressive strength indicates that there is a positive relationship between the two but also that the results are highly dispersed. This is also indicated by the low correlation coefficient indicated in Table 2.

A comparison between the best-fit curve and the estimating models shows that the ACI 318 model adjusts well for compressive strength lower than $50 \mathrm{MPa}(7250 \mathrm{psi})$ and slightly overestimates the modulus of elasticity for higher compressive strengths. The EC2 model overestimates the modulus of elasticity for compressive strength lower than $90 \mathrm{MPa}(13,050 \mathrm{psi})$. The overestimation is especially 

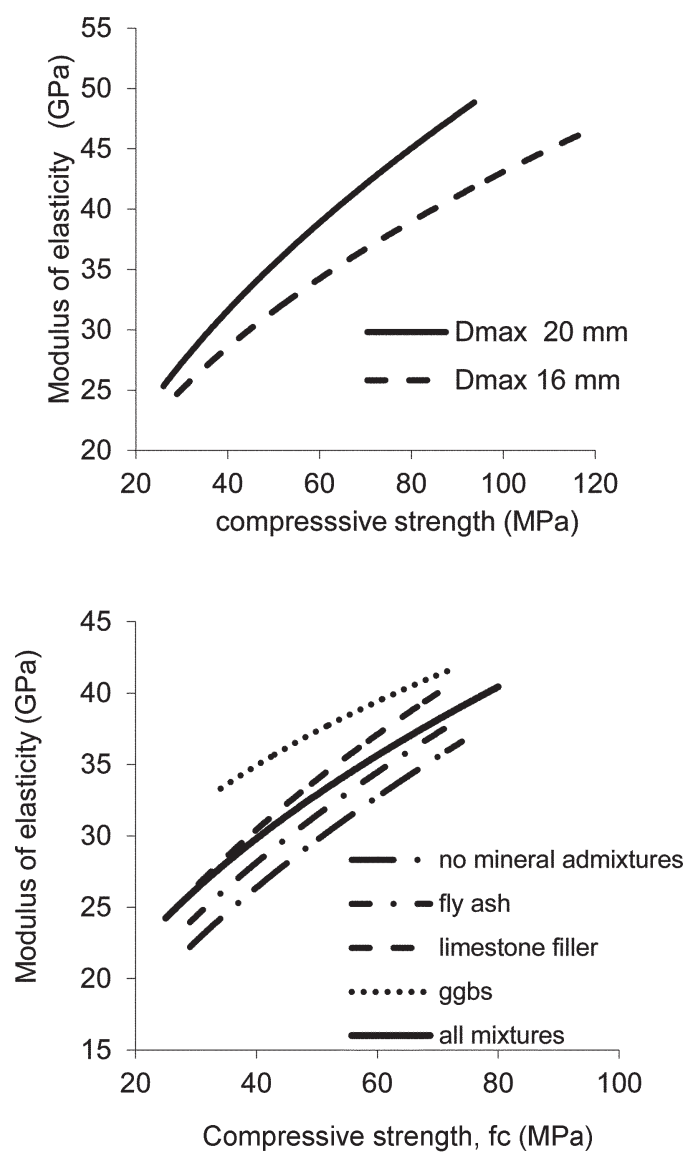

Fig. 2-Relationship between compressive strength and modulus of elasticity considering different mineral admixtures included in mixtures and maximum aggregate size. (Note: $1 \mathrm{MPa}=145 \mathrm{psi} ; 1 \mathrm{GPa}=145,000 \mathrm{psi} ; 1 \mathrm{~mm}=$ 0.03937 in.)

igh for lower compressive strength, with a maximum overestimation of approximately $20 \%$. The overestimation magnitude decreases as the compressive strength of the concrete increases. ACI 363R underestimates the modulus of elasticity. The underestimation increases to values of approximately $10 \%$ for higher compressive strength values.

It should be emphasized that, in this case, the precision of the models is evaluated with respect to the best-fit curve, which represents the mean experimental values. The most precise model, ACI 363R, is the most precise in estimating values that are close to the mean value. For many of the values that deviate from the best-fit curve, the estimation is not as precise. This phenomenon occurs because the estimating models only consider the compressive strength and are therefore not sensitive to variations in the results that are due to other variables that affect this property. These models have been well-calibrated to estimate values that are close to the mean value.

Two important variables that affect the modulus of elasticity and that are not included in the estimating model are the different mineral admixtures and the maximum aggregate size. The effect of these variables on the relationship between the compressive strength and the modulus of elasticity for the different mineral admixtures is evaluated in Fig. 2. It can be observed that the use of mineral admixtures increases the modulus of elasticity of the mixtures, and that for a given compressive strength, the modulus of elasticity is lowest for the mixtures without any mineral admixtures.
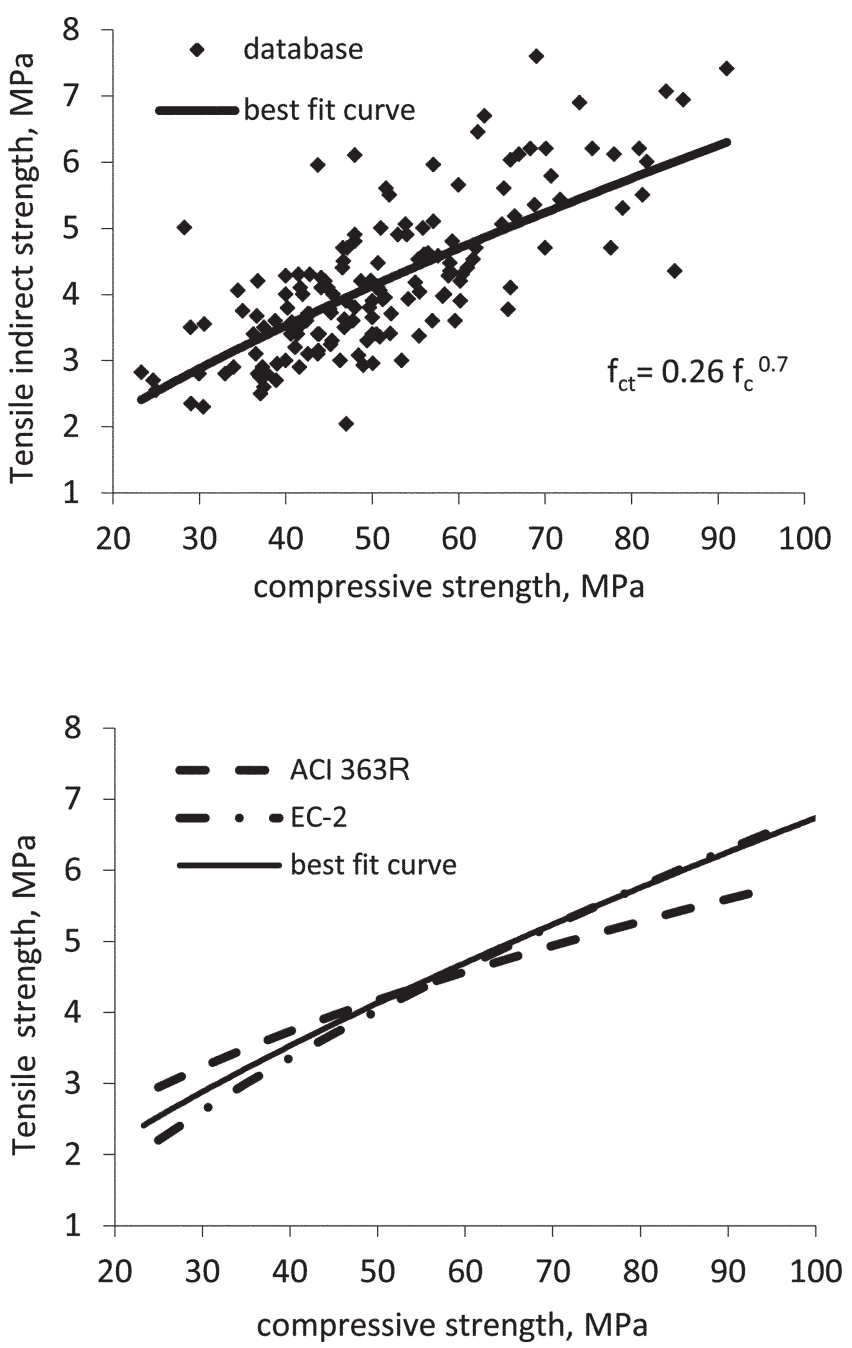

Fig. 3-Relationship between tensile strength and compressive strength for mixtures included in database and different estimating models. (Note: $1 \mathrm{MPa}=145$ psi.)

The modulus of elasticity increases in the following order for the different mineral admixture types: fly ash, limestone filler, and ground-granulated blast-furnace slag (GGBFS). It is clear that the effect of the mineral admixture type also depends on the quantities used; however, this relationship provides a general overview on the global effect of each filler type.

Regarding the maximum aggregate size, it can be observed that for a given compressive strength, the modulus of elasticity is higher for mixtures with the $20 \mathrm{~mm}(3 / 4 \mathrm{in}$.) maximum aggregate size than those with $16 \mathrm{~mm}(5 / 8 \mathrm{in}$.) maximum aggregate size.

\section{TENSILE STRENGTH ESTIMATING MODELS}

In Fig. 3, the relationship between the tensile strength and the compressive strength for all mixtures included in the database and the corresponding best-fit curve are shown. As in the case of the modulus of elasticity, there is a strong positive relationship between the two variables, but the dispersion of the data point is high. A comparison between the best-fit curve for the measured data and this relationship for the different estimating models shows that the curve of the EC2 model coincides well with the best-fit curve. For mixtures with compressive strengths higher than $40 \mathrm{MPa}$ 


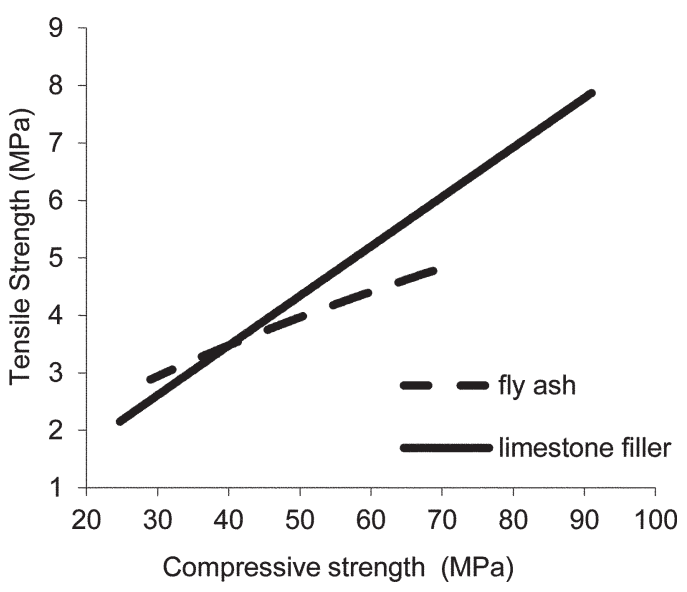

Fig. 4-Relationship between compressive strength and tensile strength for mixtures with fly ash and limestone filler (Note: $1 \mathrm{MPa}=145 \mathrm{psi}$.)

(5800 psi), the difference between the calculated values and the best-fit curve for the experimental values ranges between 0 and 5\%. For lower-strength concrete, the model underestimates the tensile strength, with a maximum underestimation of $13 \%$. In the case of the ACI 363R, it can be observed that the model overestimates the tensile strength for concretes with compressive strengths lower than $50 \mathrm{MPa}$ (7259 psi). The overestimation can reach a value of $17 \%$. For higher-strength concretes, the model underestimates the tensile strength, with a $12 \%$ maximum underestimation. As in the case of the modulus of elasticity, the two estimating models are precise in estimating tensile values that are only close to the mean values.

One important variable that affects the tensile strength, and is not included in the models, is the type of mineral admixtures used in the mixture. The effect of different mineral admixtures on the relationship between the compressive strength and the tensile strength is included in Fig. 4. For the tensile strength, there was only sufficient data to analyze the mixtures with limestone filler and fly ash. In Fig. 4, it can be observed that for compressive strengths of approximately less than $45 \mathrm{MPa}$ (6527 psi), the mixtures with limestone filler had lower tensile strength than mixtures with fly ash, and for higher compressive strengths, the mixtures with fly ash had higher compressive strengths than the mixtures with limestone filler. As in the case of the modulus of elasticity, this relationship only shows the overall effect of the two filler types on the tensile strength; it does not consider the mineral admixture content.

\section{MODULUS OF RUPTURE ESTIMATING MODELS}

In Fig. 5, the relationship between the modulus of rupture and the compressive strength for the mixtures included in the database and the corresponding best-fit curve are shown. As in the case of the modulus of elasticity and tensile strength, there is a positive relationship between the two variables, but the dispersion of the data point is high. A comparison between the best-fit curve for the measured data and this relationship for the different estimating models shows that the ACI 363R overestimates the modulus of rupture for compressive strength values lower than $70 \mathrm{MPa}(10,150 \mathrm{psi})$, with a $23 \%$ maximum overestimation, and underestimates the modulus of rupture for high compressive strengths, with a maximum 5\% underestimation. The EC2 model generally
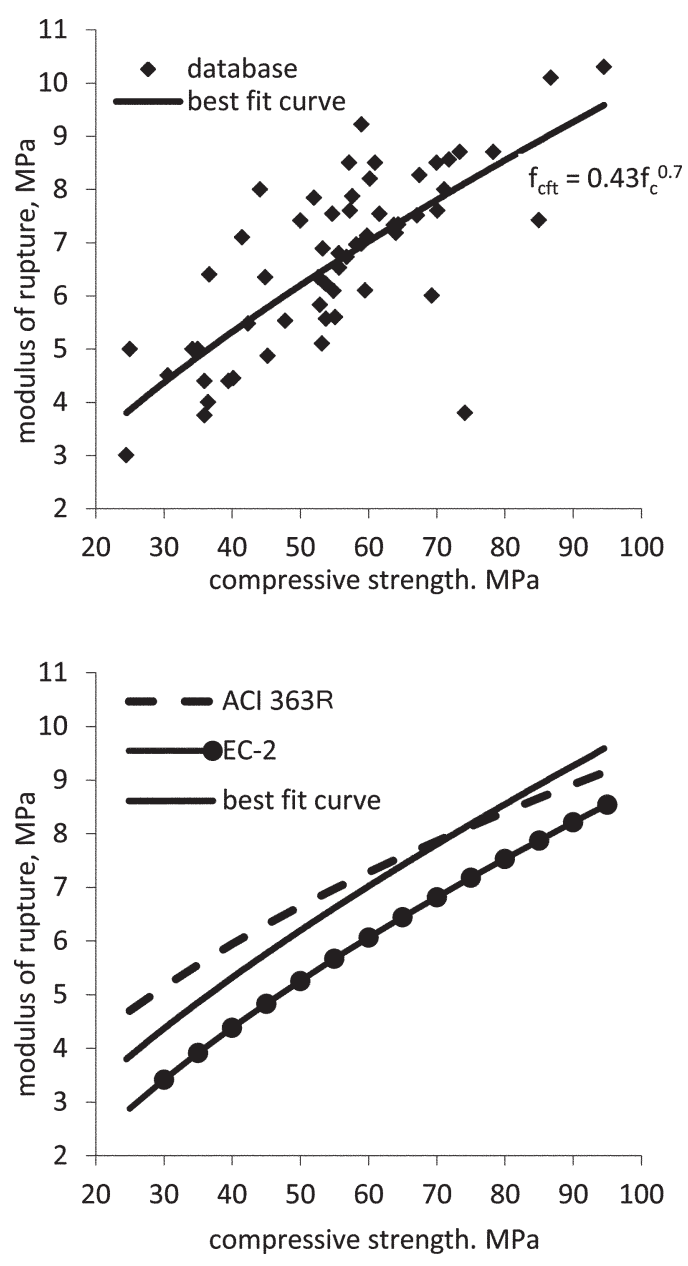

Fig. 5-Relationship between modulus of rupture and compressive strength for mixtures included in database and different estimating models. (Note: $1 \mathrm{MPa}=145 \mathrm{psi}$.)

underestimates the modulus of rupture for all the concretes, with approximately 25\% underestimation for the loweststrength concrete and up to $10 \%$ underestimation for the highest-strength concrete.

Overall, the modulus of rupture estimating models are less precise in comparison with the models for the other two characteristics. However, also in this case, the precision is in estimating values that are close to the mean values, and here again, the dispersion is quite high with a significant number of data points deviating substantially from the best-fit curve.

\section{COMPARISON BETWEEN CALCULATED AND MEASURED VALUES}

The following section includes a comparison between the experimentally measured values obtained from the literature and the values calculated for each of these mixtures using the different estimating models. Figures 6 to 8 include as reference the relationship $y=x$, which represents the condition of equal values for the calculated and measured characteristics, and the target deviation limit between the calculated and measured values that corresponds to the $90 \%$ confidence interval. The accuracy of the models in estimating the mechanical properties of SCC is analyzed by comparing the experimentally measured values and the calculated values.

In this type of analysis, the model that best estimates the mechanical property is the model that has most of the 

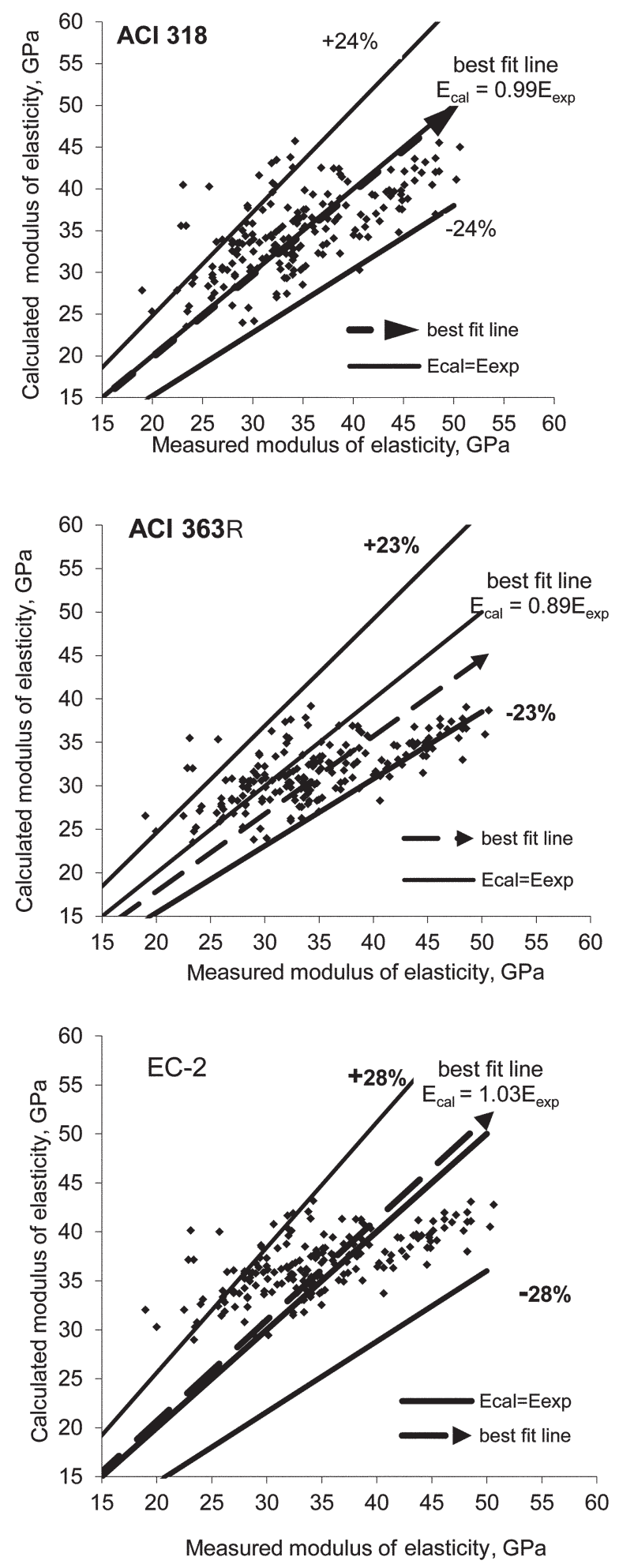

Fig. 6-Relationship between measured modulus of elasticity and calculated values for different estimating models. (Note: $1 \mathrm{MPa}=145 \mathrm{psi} ; 1 \mathrm{GPa}=145,000$ psi.)

data points centered around the reference line $(x=y)$ and with the smallest deviation margins. The model underestimates the value if the majority of the points are located below the reference line and overestimates it if the majority of the points are above the reference line. The analysis also includes the best-fit line, calculated from linear regression analysis, which gives the overall tendency of the model in comparison to the reference line.
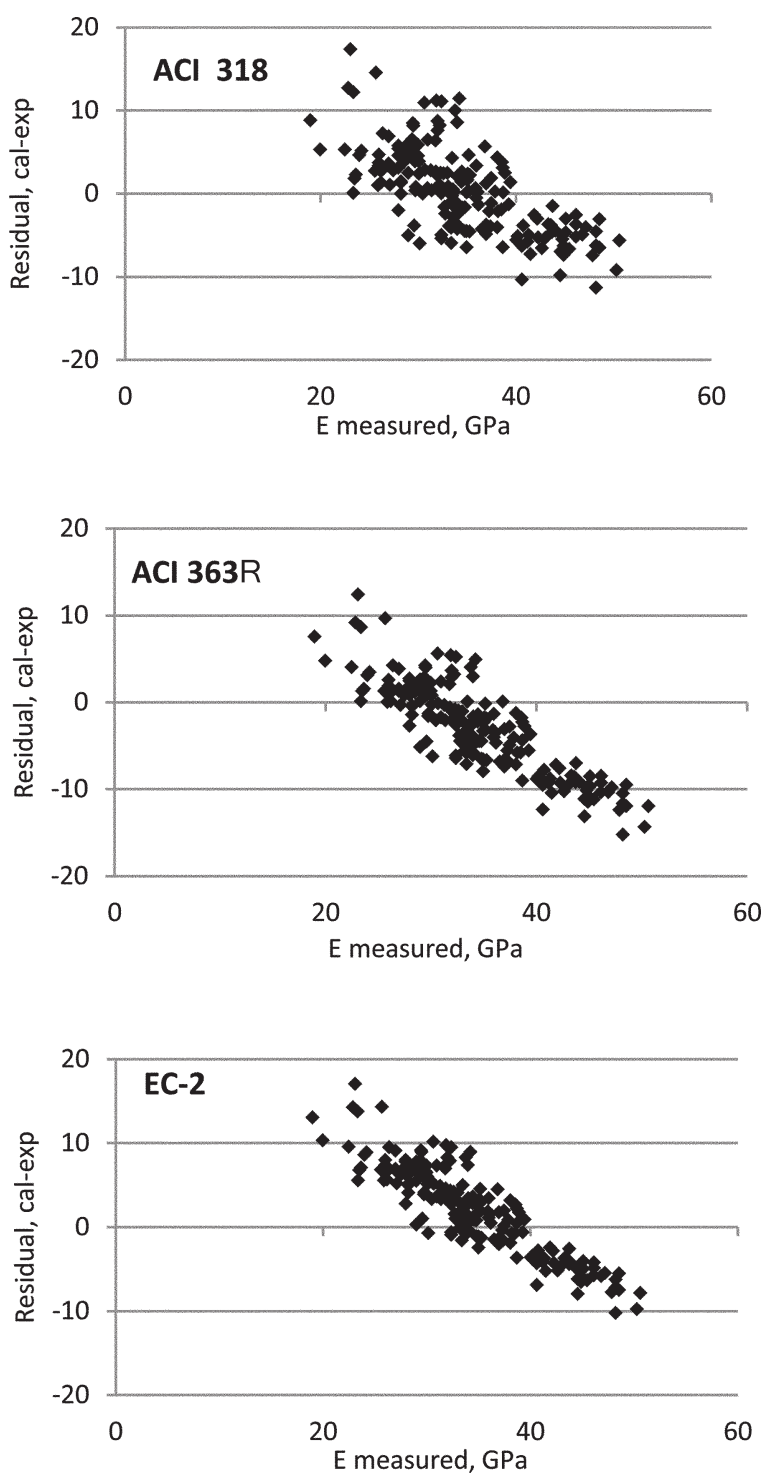

Fig. 7-Measured modulus of elasticity versus residual values. (Note: $1 \mathrm{GPa}=145,000$ psi.)

\section{Modulus of elasticity}

In Fig. 6, the relationship between the measured and the calculated values for the modulus of elasticity estimating models is considered. For a $90 \%$ confidence interval, the ACI 363R model is the most precise, with $\pm 23 \%$ deviation from the reference line, followed by the ACI 318 model and EC2, with values of $24 \%$ and $28 \%$, respectively.

Comparing the best-fit line with the reference line, it can be observed that the EC2 and ACI 318 models are more precise with a slope of the best-fit line of approximately 1.0. The ACI 363R model underestimates the modulus of elasticity with a slope of 0.89 .

From evaluating the distribution of the data points, it can be observed that in the case of the ACI 363R model, the data points are well-distributed within the marked deviations, with only a few points below and above the marked margins. For the ACI 318 model, most points are well-distributed within the marked margins; however, some data points pass the upper marked limit. In the case of the EC2 model, the data points are distributed in a more horizontal band, with a higher concentration in the upper range of the marked margins. 

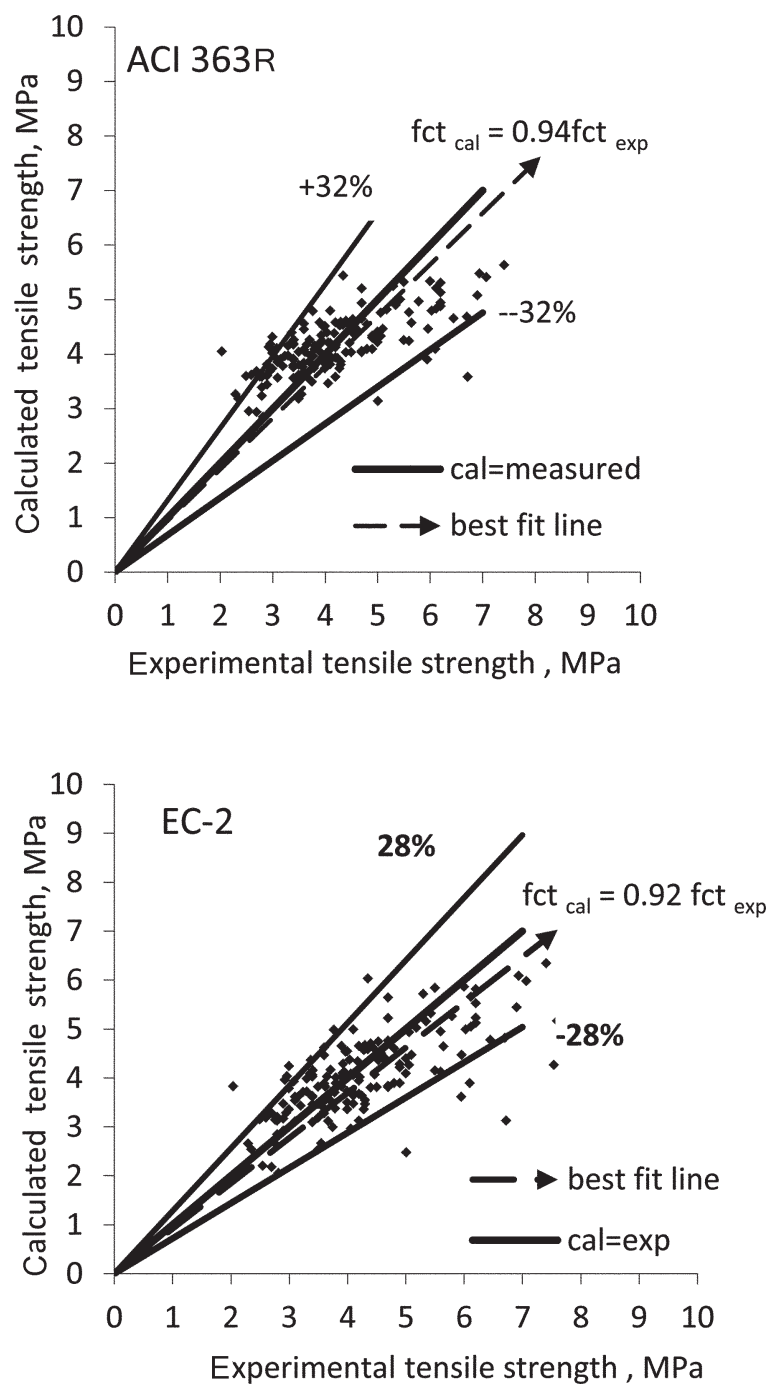

Fig. 8-Relationship between experimental tensile strength and calculated values for different estimating models. (Note: $1 \mathrm{MPa}=145$ psi.)

It is interesting to note that for all the models, the measured range within which the data points are distributed is much wider than for the calculated ones, and the data points tend to form a horizontal band, centered around the mean value. This reflects the strong tendency of the models to better estimate mean values and their limited capacity in estimating values that are not centered around the mean.

This phenomenon can also be observed in Table 3. The mean modulus of elasticity of the ACI 318 model is very close to the experimental mean, with values of 34.94 and $34.57 \mathrm{GPa}$ (5066 and $5013 \mathrm{ksi}$ ), respectively. The EC2 model slightly overestimates the mean, with a value of $36.66 \mathrm{GPa}$ (5317 ksi), and the ACI 363R model underestimates the measured mean, with a value of $31.58 \mathrm{GPa}$ (4579 ksi). For all models, the standard deviation of the calculated values is lower than that of the experimental value, which has a value of $6.73 \mathrm{GPa}(976 \mathrm{ksi})$.

An alternative method to evaluate the performance of the different estimating models is using the residual analysis. The residual value $R$ is defined as the difference between the estimated and the measured value: $R=$ estimated value - measured value.
Table 3-Modulus of elasticity: statistical parameters for evaluating different estimating models

\begin{tabular}{|c|c|c|c|c|}
\hline & \multicolumn{4}{|c|}{ Modulus of elasticity, GPa (ksi) } \\
\hline & \multirow[b]{2}{*}{ Measured } & \multicolumn{3}{|c|}{ Calculated } \\
\hline & & ACI 318 & ACI 363R & $\mathrm{EC} 2$ \\
\hline Minimum & $\begin{array}{l}19.00 \\
(2755)\end{array}$ & $\begin{array}{l}23.50 \\
(3408)\end{array}$ & $\begin{array}{l}23.50 \\
(3408)\end{array}$ & $\begin{array}{l}28.96 \\
(4199)\end{array}$ \\
\hline Maximum & $\begin{array}{l}50.64 \\
(7343)\end{array}$ & $\begin{array}{l}45.70 \\
(6627)\end{array}$ & $\begin{array}{l}39.18 \\
(5681)\end{array}$ & $\begin{array}{l}43.16 \\
(6258)\end{array}$ \\
\hline Mean $m$ & $\begin{array}{c}34.57 \\
(5013)\end{array}$ & $\begin{array}{l}34.94 \\
(5066)\end{array}$ & $\begin{array}{c}31.58 \\
(4579)\end{array}$ & $\begin{array}{l}36.66 \\
(5316)\end{array}$ \\
\hline Standard deviation & $6.73(976)$ & $4.93(715)$ & $3.48(505)$ & $3.12(452)$ \\
\hline $\begin{array}{l}\text { Coefficient of } \\
\text { variation }\end{array}$ & 0.19 & 0.14 & 0.11 & 0.09 \\
\hline$m_{\text {calculated }}-m_{\text {measured }}$ & - & $0.37(54)$ & $-2.99(434)$ & $2.09(303)$ \\
\hline \multirow{3}{*}{ Residual analysis } & $\begin{array}{c}\% \text { “+” } \\
\text { residuals }\end{array}$ & 56 & 30 & 66 \\
\hline & $\begin{array}{l}\% \text { “-” } \\
\text { residuals }\end{array}$ & 44 & 70 & 34 \\
\hline & $\begin{array}{l}\text { Mean } \\
\text { residual }\end{array}$ & $4.16(603)$ & $4.80(696)$ & $4.71(605)$ \\
\hline
\end{tabular}

In Fig. 7, the residuals of the SCC mixtures are plotted as a function of the experimental values for the different estimation models. Positive residuals indicate that the model overestimates the mechanical characteristic evaluated and negative residuals indicate that the model underestimates it. A model better predicts the mechanical property if the residuals are closely centered around the zero axis and if these are equally distributed in the positive and negative ranges. Only having the residuals equally distributed around the zero axes indicates a better capability of the model to estimate the mean value well. A low absolute residual value is an indication to the overall precision of the model. The distributions of the residuals in the negative and positive ranges for the different models are included in Table 3.

From Fig. 7, it can be observed that in all models the data points are centered around a negatively sloped line, indicating that there is a direct negative relationship between the residuals and the measured modulus of elasticity. Ideally, the model should be independent of the experimental values, and there should be no relationship between the two. In this case, the models overestimate the value when the modulus of elasticity is low (positive residual) and underestimate it (negative residuals) when the modulus of elasticity is high. It is interesting to note that for all models, this line crossed the $\mathrm{x}$-axis (residuals of approximately zero) at around $35 \mathrm{GPa}$ (5075 ksi). This value corresponds approximately to the measured mean and the calculated mean, as shown in Table 3. It can also be noted that in the case of the EC2 model, the points are less disperse than in the case of the other three models, as also reflected by its lower standard deviation.

When comparing the percentage of values with positive and negative residuals, it can be observed that the ACI 318 model shows the best and most balanced results, with $56 \%$ positive residuals; the ACI 363R model significantly underestimates it with $70 \%$ negative residuals; and the EC2 model tends to overestimate the modulus of elasticity, with $66 \%$ positive residuals. 


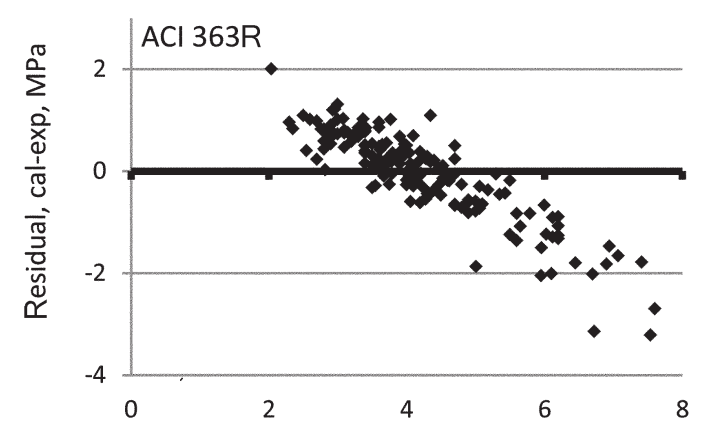

Experimental tensile strength, $\mathrm{MPa}$

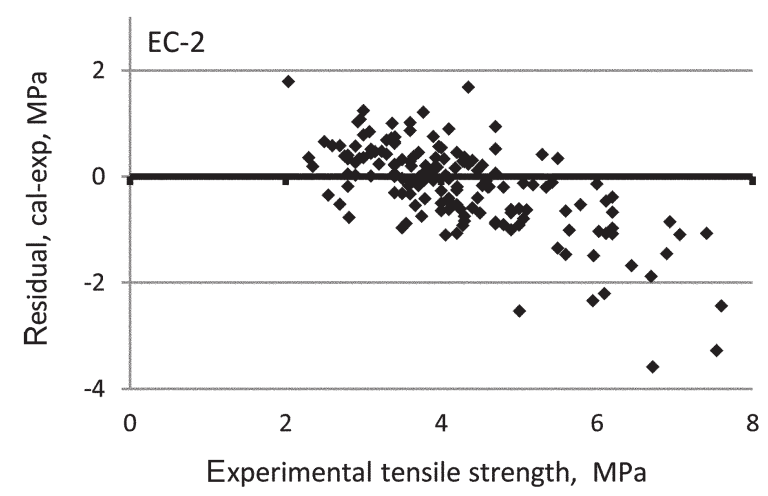

Fig. 9-Measured tensile strength versus residual values. (Note: $1 \mathrm{MPa}=145$ psi.)

Comparing the combined mean residual (positive and negative residuals) in Table 3 , it can be observed that the ACI 318 model has the lowest mean residual (4.16 GPa [603 ksi]), followed by the EC2 and ACI 363R models, with values of 4.23 and $4.71 \mathrm{GPa}$ (603 and $605 \mathrm{ksi}$ ), respectively. These results again emphasize the overall tendency of the models to estimate precisely only values that are close to the mean value.

Considering the various analysis procedures applied, it can be observed that the most precise model in calculating the modulus of elasticity of SCC is the ACI 318 model, and the most inaccurate model is the ACI 363R model.

\section{Tensile strength}

The relationship between the measured tensile strength for all the mixtures included in the database and the calculated values using the different estimating models is shown in Fig. 8. Comparing the deviation from the reference line, the EC2 model is more accurate than the ACI 363R model, with a $90 \%$ confidence interval that corresponds to a $\pm 28 \%$ deviation, in comparison with a $\pm 32 \%$ deviation for the ACI $363 \mathrm{R}$ model. For the EC2 model, however, the data points are more evenly distributed within the marked margins in comparison with the data points of the ACI 363R model, where the data points are distributed in a more horizontal band, reflecting a stronger tendency to estimate only mean values.

Comparing the best-fit lines, it can be observed that both the ACI 363R and EC2 models slightly underestimate the tensile strength with similar slopes of 0.94 and 0.92 , respectively, and the calculated results are within a narrower range of values in comparison with the experimental values, which spread over a wider range of values.
Table 4-Tensile strength: statistical parameters for evaluating different estimating models

\begin{tabular}{l|c|c|c}
\hline \multirow{2}{*}{} & \multicolumn{3}{|c}{ Tensile strength, MPa (psi) } \\
\cline { 2 - 4 } & Experimental & ACI 363R & EC2 \\
\cline { 2 - 4 } & $2.04(296)$ & $2.85(413)$ & $2.05(297)$ \\
\hline Minimum & $7.60(1102)$ & $5.63(816)$ & $6.34(919)$ \\
\hline Maximum & $4.24(615)$ & $4.18(606)$ & $4.05(587)$ \\
\hline Mean $m$ & $1.16(168)$ & $0.54(78)$ & $0.84(122)$ \\
\hline Standard deviation & 0.27 & 0.13 & 0.21 \\
\hline \multirow{2}{*}{$m_{\text {calculated }}-m_{\text {measured }}$} & - & $-0.06(-9)$ & $-0.19(-28)$ \\
\hline \multirow{2}{*}{ Residual analysis } & $\%$ “+” residuals & 54 & 45 \\
\cline { 2 - 4 } & $\%$ “-” residuals & 46 & 55 \\
\cline { 2 - 4 } & Mean residual & $0.66(96)$ & $0.62(90)$ \\
\hline
\end{tabular}

Comparing the parameters in Table 4 , it can be observed that the mean tensile strength of the ACI 363R and EC2 models are very close to the experimental mean, with values of 4.18, 4.05, and 4.24 MPa (606, 587, and $615 \mathrm{psi})$, respectively. For both models, the standard deviation of the calculated values is lower than that of the experimental standard deviation, which has a value of 1.16 .

In the case of the residual analysis for the tensile strength, it can also be observed in Fig. 9 that there is a direct negative relationship between the residuals and the experimental value. Also in this case, the models overestimate the value when the tensile strength is low (positive residual) and underestimate it (negative residuals) when the tensile strength is high. For both models, the best-fit line crossed the x-axis (residuals of approximately zero) at approximately the mean calculated value, as indicated in Table 4 . It can also be noted that in the case of the EC2 model, the data points are more disperse than in the case of the other three models. This is also reflected by its higher standard deviation of 0.84 .

Considering the percentage of values with positive and negative residuals, it can be observed that the ACI 363R model shows the best and most balanced results, with $54 \%$ positive residuals, in comparison with $45 \%$ positive residuals for the EC2 model.

Comparing the combined mean residual (positive and negative residuals) in Table 4 , it can be observed that the EC2 model has a lower mean residual of $0.62 \mathrm{MPa}$ (90 psi), in comparison with a value of $0.66 \mathrm{MPa}$ (96 psi) for the ACI 363R model.

Considering the various analysis procedures applied, it can be observed that the EC 2 model is more accurate that the ACI 363R model in estimating the tensile strength of SCC.

\section{Modulus of rupture}

The equations for the modulus of rupture of the ACI 363R and EC2 models are included in Table 1. In Fig. 10, it can be observed that for the modulus of rupture there are less data points than for the other two cases-only 59 data points-in comparison with 193 for the modulus of elasticity and 165 for the tensile strength. Comparing the best-fit lines, the ACI 363R model is more precise with a slope of 1 . The EC2 model underestimates the modulus of rupture with slopes of 0.83 . 

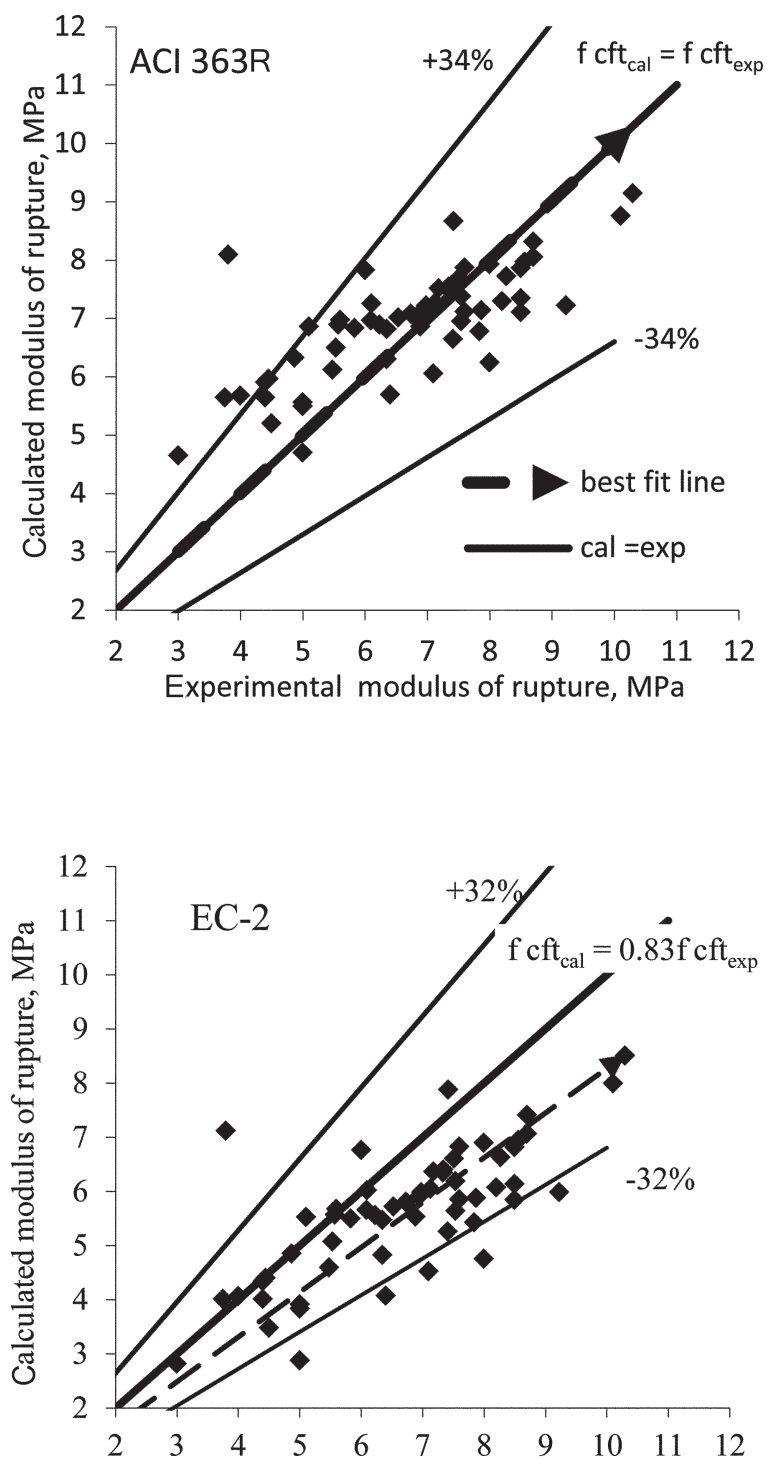

Experimental modulus of rupture, $\mathrm{MPa}$

Fig. 10-Relationship between measured modulus of rupture and calculated values for different estimating models. (Note: $1 \mathrm{MPa}=145$ psi.)

In the case of the EC2 model, data points are better distributed in a slope, indicating that the spread of the calculated values is more similar to the experimental spread. In the ACI 363R model, the data points are distributed in a more horizontal band, showing a lower discriminatory capability of the model and a stronger tendency of the model to better estimate values that are closer to the mean value.

Considering a $90 \%$ confidence interval, the deviation from the reference line is higher from the modulus of rupture that for the modulus of elastic and tensile strength, with values of $\pm 34 \%$ for the ACI $363 \mathrm{R}$ model and $\pm 32 \%$ for the EC2 models, indicating the lower precision of these models.

Comparing the statistical parameters in Table 5, it can be observed that mean modulus of rupture of the ACI 363R model is the closest to the experimental mean, with values of 6.97 and $6.74 \mathrm{MPa}$ (1011 and $977 \mathrm{psi}$ ), respectively. The EC2 model underestimates the mean modulus of rupture, with values of 5.69 MPa (825 psi). For the ACI 363R model,
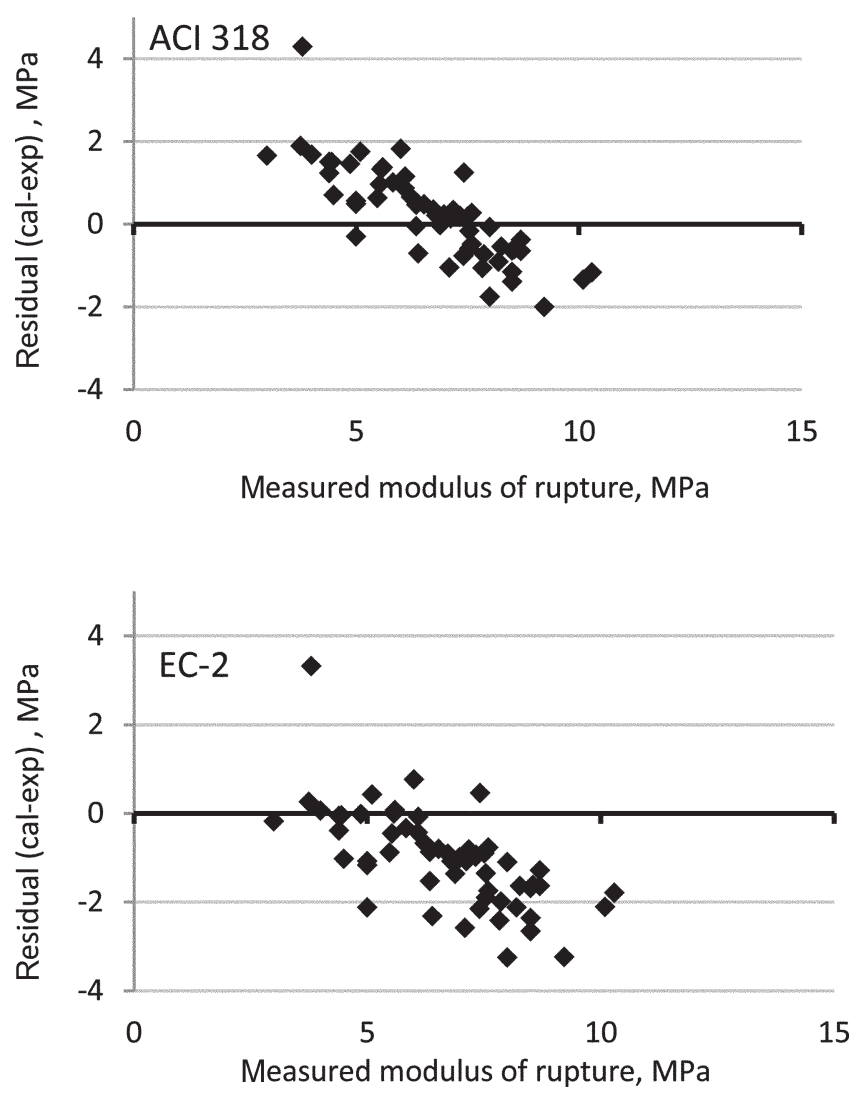

Fig. 11-Measured modulus of rupture versus residual values. (Note: $1 \mathrm{MPa}=145 \mathrm{psi}$.)

Table 5-Modulus of rupture: statistical parameters for evaluating different estimating models

\begin{tabular}{l|c|c|c}
\hline \multirow{2}{*}{} & \multicolumn{3}{|c}{ Modulus of rupture, MPa (psi) } \\
\cline { 2 - 4 } & \multirow{2}{*}{ Measured } & \multicolumn{2}{|c}{ Calculated } \\
\cline { 2 - 4 } & $3.00(435)$ & $4.65(674)$ & $2.82(409)$ \\
\hline Minimum & $10.30(1494)$ & $9.14(1325)$ & $8.51(1234)$ \\
\hline Maximum & $6.74(977)$ & $6.97(1011)$ & $5.69(825)$ \\
\hline Mean $m$ & $1.68(244)$ & $0.99(144)$ & $1.26(183)$ \\
\hline Standard deviation & 0.25 & 0.14 & 0.22 \\
\hline Coefficient of variation & - & $0.23(33)$ & $-1.05(-152)$ \\
\hline$m_{\text {calculated }}-m_{\text {measured }}$ & $\%$ “+” residuals & 58 & 12 \\
\hline \multirow{2}{*}{ Residual analysis } & $\%$ “-” residuals & 42 & 88 \\
\cline { 2 - 4 } & Mean residual & $0.89(129)$ & $1.24(180)$ \\
\hline
\end{tabular}

the standard deviation of the calculated values are significantly lower than that of the experimental values, which has a value of $1.68 \mathrm{MPa}$ (244 psi).

As in the case of the modulus of elasticity and the tensile strength, there is also a direct negative relationship between the residuals and the experimental value of the modulus of rupture, as shown in Fig. 11. As the value of the measured modulus of rupture increases, the magnitude of the residuals decreases. In the case of the EC2 model, the majority of the residuals are negative, reflecting the tendency to underestimate the value. It can also be noted that in the case of the 
EC2 model, the points are more dispersed than in the case of the ACI 363R model. This is also reflected by a high standard deviation value of 1.26 .

When comparing the percentage of values with positive and negative residuals, it can be observed that the ACI 363R model shows the best and most balanced results, with $58 \%$ positive residuals. The EC2 model significantly underestimates the modulus of rupture, with $88 \%$ negative residuals. Comparing the combined mean residual (positive and negative residuals) in Table 5, it can be observed that the ACI 363R model has a lower mean residual than the EC2 model, with values of 0.89 and $1.24 \mathrm{MPa}$ (129 and $180 \mathrm{psi}$ ), respectively.

Considering the various analysis procedures applied, it can be observed that the ACI 363R model better predicts the modulus of rupture of SCC than does the EC2 model.

\section{CONCLUSIONS}

This study presents an extensive database of mechanical properties' results for SCC and evaluates various estimating models and their applicability to this type of concrete. The models considered are ACI 318, ACI 363R, and EC2. A comparison between the measured data collected from the literature and the calculated values using the current estimating models and a detailed analysis of the results permits to establish the following conclusions:

1. In terms of general applicability, the three models evaluated are suitable for the estimating the modulus of elasticity, tensile strength, and modulus of rupture of SCC.

2. The ACI 318 model is the most accurate in the case of the modulus of elasticity, the EC2 model is more accurate in the case of the tensile strength, and the ACI 363R model is more accurate for the modulus of rupture.

3. Regarding the dispersion of the results, it is important to point out that in all cases, the calculated values have less dispersion than the measured results. This indicates that the models do not detect the existing variability shown by the measured results of the mechanical characteristics and have a strong tendency to estimate values that are close to the mean values. This is also reflected by the negative relationship between the residuals and the measured values. Similar studies carried out on conventional concrete show the same tendency of the models to adjust to mean values with a relatively low standard deviation, implying a lack in their discriminatory capability.

4. It is noteworthy that all models use the compressive strength to characterize the concrete, and even though the models are adequately adjusted to match the mean values, they do not consider other variables related to the raw materials used which, in the case of SCC, may be important.

5. Considering a $90 \%$ confidence interval, for the modulus of elasticity, the results show $\pm 24 \%, \pm 23 \%$, and $\pm 28 \%$ deviation for the ACI 318, ACI 363R, and EC2 models, respectively. For the tensile strength, the deviations are $\pm 28 \%$ and $\pm 32 \%$ for the EC2 and ACI 363R models, respectively. For the modulus of rupture, the deviations are $\pm 32 \%$ and $\pm 34 \%$ for the EC2 and ACI 363R models, respectively.

\section{REFERENCES}

1. Attiogbe, E.; See, H.; and Daczko, J., "Engineering Properties of Self-Consolidating Concrete," First North American Conference on the Design and Use of Self Consolidating Concrete, ACBM, Chicago, IL, 2002, pp. 331-336.

2. Holschemacher, K., and Klug, Y., "A Database for the Evaluation of Hardened Properties of SCC," Lacer, No. 7, 2002, pp. 123-134.

3. Ouchi, M.; Nakamura, S.; Osterberg T.; Hallberg, S.; and Lwin M., "Applications of Self Compacting Concrete in Japan, Europe and the United States," ISHPC Report, 2003, pp. 1-20.

4. Marti, J.; Serna, P.; Arbelaez, C.; and Rigueira, V., "Comportamiento Adherente del Hormigón Autocompactante en Transmisión y Anclaje," Materiales de Construcción, V. 56, No. 284, 2006, pp. 27-42. (in Spanish)

5. Leemann, A., and Hoffmann, C., "Properties of Self-Compacting and Conventional Concrete-Differences and Similarities," Magazine of Concrete Research, V. 57, No. 6, Aug. 2005, pp. 315-319.

6. Turcry, P.; Loukiki, A.; and Haidar, K., "Mechanical Properties, Plastic Shrinkage, and Free Deformations of Self-Consolidating Concrete," First North American Conference on the Design and Use of Self-Consolidating Concrete, ACBM, Chicago, IL, 2002, pp. 335-340.

7. Vilanova, A., "Influencia de la Dosificación y Empleo de Diferentes Tipos de Cemento y Adiciones en las Propiedades Mecánicas del Hormigón Autocompactante," doctoral thesis, Escuela de Ingenieros de Caminos, Canales y Puertos, Departamento de Ingeniería Civil: Construcción, Universidad Politécnica de Madrid, 2009. (for a digital copy of the database, contact agranati@gmail.com) (in Spanish)

8. ACI Committee 318, "Building Code for Structural Concrete (ACI 318-08) and Commentary," American Concrete Institute, Farmington Hills, MI, 2008, 473 pp.

9. ACI Committee 363, "Report on High-Strength Concrete (ACI 363R92)," American Concrete Institute, Farmington Hills, MI, 1992, 55 pp.

10. EN 1992-1-1, "Eurocode 2: Design of Concrete Structures," European Committee for Standardization, Brussels, Belgium, Dec. 2004. 